\title{
Dengue Awareness and Practice Among The People Living in Haraincha Village Development Committee of Eastern Nepal
}

\author{
KC Heera, ${ }^{1^{*}}$ Parajuli $S B^{2}$
}

\begin{abstract}
Affiliation:
1. College of Nursing, B. P. Koirala Institute of Health Sciences, Dharan-18, Sunsari, Nepal.

2. Lecturer, Department of Community Medicine, Birat Medical College \& Teaching Hospital, Tankisinuwari-02, Morang, Nepal.
\end{abstract}

\section{ARTICLE INFO \\ Article History \\ Received : 8Aug, 2016 \\ Accepted : 9Sep, 2016 \\ Published : $20 \mathrm{Dec}, 2016$}

(C) Authors retain copyright and grant the journal right of first publication with the work simultaneously licensed under Creative Commons Attribution License CC - BY 4.0 that allows others to share the work with an acknowledgement of the work's authorship and initial publication in this journal.

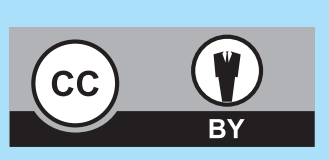

* Corresponding Author Ms. Heera KC

MSc. Nursing Student

College of Nursing

B. P. Koirala Institute of Health Sciences

Dharan-18, Sunsari, Nepal

Email: heerakc2011@gmail.com

Orcid ID: 0000-0003-3768-8542

\section{Citation}

KC Heera, Parajuli SB. Dengue Awareness and Practice Among The People Living in Haraincha Village Development Committee of Eastern Nepal. BJHS2016;1(1) 1:38-46.

\section{ABSTRACT}

\section{Introduction}

Dengue is an emerging public health problem across the globe. Almost $50 \%$ of world's populations are at risk. In Nepal, the first dengue case was reported in 2004. Three major epidemics have occurred since then: in the year 2006, 2010 and 2012. Since there is no specific treatment and vaccine available, awareness is vital to prevent and control it.

\section{Objective}

This study aimed to assess dengue awareness and prevention practice among the people living in Haraincha Village Development Committee of Morang District in Eastern Nepal.

\section{Methodology}

A community based cross-sectional study was conducted from $15^{\text {th }}$ October 2013 to $30^{\text {th }}$ November 2013. Data was collected from 122 households by means of interview using semi structured questionnaires and analyzed in SPSS.

\section{Results}

Two percent had history of dengue contracted outside the country. Almost half were aware about dengue. Among them, 91.7\% rightly said that dengue is transmitted during rainy season. The most common mode of transmission cited by them was mosquito bite (83.3\%) and only two percent rightly said that biting species is Aedes. Ninety two Percent had wrong belief that stagnant dirty water was common breeding site. The common symptoms stated were fever $(80 \%)$, headache $(50 \%)$, myalgia (36\%), and retro-orbital pain (7\%). Almost $92 \%$ were aware that dengue is preventable and $68 \%$ knew that treatment is available. The common methods of control practiced were using bed nets (81.83\%), spray (51.77\%), coil (38.41\%) and window-door screen (38.41\%). Gender $(p=<0.001)$, ethnicity $(p=0.004)$, education $(p=0.020)$ poverty $(p=.006)$ and natural light inside the household $(p=0.002)$ had significant association with respondent being aware of dengue.

\section{Conclusion}

Dengue awareness was not adequate among the residents of Haraincha although preventive practices regarding vector control was noted.

\section{KEY WORDS}

Awareness, dengue, eastern Nepal, practices 


\section{INTRODUCTION}

Dengue infection is a viral disease transmitted to humans by bite of infected Aedes mosquitoes. This rapidly expanding vector born disease has become an important public health challenge with an economic burden that is currently unmet by non availability of vaccines, specific therapeutic agents or efficient vector control strategies. ${ }^{1}$ Dengue is found in tropical and subtropical areas around the world, mainly in urban and semi-urban areas. The first epidemic was recorded in 1635 AD. ${ }^{2}$ Rush described it as "break-bone fever". World health organization (WHO) currently estimates 50-100 million dengue infections worldwide every year. ${ }^{2}$ The disease is now endemic in more than 100 countries in Africa, the Americas, the Eastern Mediterranean, South-east Asia and the Western Pacific. ${ }^{2}$ An estimated 0.5 million people with severe dengue require hospitalization each year. About $2.5 \%$ of those affected die. ${ }^{2}$ Of the 2.5 billion people around the world living in dengue endemic countries and at risk of contracting Dengue fever/Dengue hemorrhagic fever, 1.3 billion live in 10 countries of the WHO South-East Asia. Nepal reported its first indigenous case in November 2004 from Chitwan district in Japanese volunteer. Hospitals in Western and Central Terai as well a hospital in Kathmandu reported 32 laboratory confirmed dengue during September -October 2006, following dengue epidemic in India. From the year 2007 to 2009; 27, 10 and 30 confirmed cases were reported respectively. However in 2010, dengue epidemic occurred in several locations in lowland districts as well as some hilly areas. According to Epidemiology and Disease Control Division, 917 were serologically confirmed and 5 deaths were reported. In 2011, 2012 and 2013; 79, 183 and 700 confirmed cases were reported in Nepal respectively. Jhapa district alone reported 72 confirmed cases in $2012^{3}$. These reported cases were just only the tip of iceberg. ${ }^{2}$ There are four distinct, but closely related serotypes of the virus causing dengue. Recovery from infection by one serotypes provides lifelong immunity. However there is an increased risk of developing severe dengue by subsequent infections through other serotypes. ${ }^{4}$ Aedes aegypti and Aedes albopictus are the two major vectors for dengue transmission. Aedes mosquito, a peri-domestic and domestic day biter, breeds mainly on clean stagnated water collected after rainfall in water tanks, pools, coolers, flower vases, coconut shells, construction sites, overhead uncovered or partially covered water tanks, discarded buckets, artificial ponds, containers left in or around the houses, empty cans, bottles and automobile tires. The mosquitoes rest indoors on various objects such as closed and dark places and outside in cool and shady places. The vector Aedes though can fly only to a distance of 400 meters but can be spread mechanically through various types of vehicles used by man over a vast distances. ${ }^{2}$ The transmission of dengue depends upon two factors i.e. biotic: vector and the host and abiotic: temperature, humidity and rainfall. ${ }^{3}$ There is increased viral load in human blood two days before onset of fever and lasts for 5-7 days after the onset of the fever. The vector aedes gets infected during these two periods and thereafter human become dead-end for transmission. ${ }^{1}$ As the host (infected man) moves from one part to another there is increased risk of occurrence of infections. ${ }^{3}$ A Study conducted by Milan Lopchan et al. found that $44.1 \%$ had poor knowledge of dengue..$^{5}$ In a study by Anita Acharya et al. carried out among 641 people and found $90 \%$ of the respondents had heard about dengue where $68 \%$ cited as mosquito bite being a most common cause. Regarding knowledge about preventive measures, majority (70.3\%) knew about mosquito repellents like mat, liquid vaporizers and coils. ${ }^{6}$ The clinical pattern of dengue remains asymptomatic in more than $50 \%$ cases and also many people often get confused with viral illness therefore, it is vital to recognize at the earliest signs and symptoms, multi-system involvement pattern in dengue to reduce the mortality. Creating awareness regarding dengue and its prevention practices is only the best way to control its transmission to healthy people. Furthermore, studies on this topic are needed to be highly emphasize in Nepal especially in those areas where chances of transmission is very high and to find the present status. The objective of this study was to find the existing knowledge and prevention practices of dengue among the residents of Haraincha VDC, a peri-domestic area of Morang district.

\section{METHODOLOGY}

A community based cross-sectional study was conducted from $15^{\text {th }}$ October 2013 to $30^{\text {th }}$ November 2013 in Haraincha VDC of Morang District. The data was collected from 122 households by means of interview using a pre tested semi structured questionnaires. The sample size was calculated based on the similar research conducted in Chitwan district of central Nepal. ${ }^{5}$ The Stratified random sampling method was used to select sample in this study. As Haraincha VDC was divided into 9 wards, each ward was taken as strata. After selection of household, one person preferably head of household was selected for interview. Information was collected for socio-demographic characteristics of the participants, their awareness and preventive practices regarding dengue. Both gender of age more than 15 years willing to participate were included. Informed consent was obtained prior to data collection. The confidentiality was maintained by assigning unique code to the respondents' name in the interview form, not disclosing the respondents' information to others and using the information for the study purpose only. The collected data was checked thoroughly for completeness and was entered in Microsoft excel. The entered data was checked, verified and was transferred to Statistical Package for Social Sciences (SPSS) 17 for analysis. The descriptive analysis was presented in table and pie chart with frequency, percentages, mean and standard deviations. 
Chi Square test was applied to see the association between awareness status (those who heard about dengue) and background variables and $p$ value of less than 0.05 was considered statistically significant.

\section{RESULTS}

A community based cross sectional study was conducted in Haraincha Village Development Committee of Eastern Nepal. Dengue awareness and practices were assessed in 122 household. The study finding revealed that the male respondents were more (61.5\%) than female. Every three out of ten belonged to age group of 31-40 years. Majority caste/ethnic groups under study were Brahmin/Chhetri (36.9\%), Terai caste (36.1\%) and least were Dalits (4.1\%). Majority $(82.8 \%)$ were married. Three in ten had completed their secondary level of education and having major occupation as agriculture (45.9\%). Almost half were from nuclear family having average family size of 5.76. Fifty-four percent were above the poverty line. Almost $25 \%$ had traveled outside the country during last 1 year. Majority traveled to Malaysia, where dengue is known epidemic.

As shown in table 1 , only $49.2 \%$ heard about dengue and their major source of information was TV/Radio (65\%) followed by newspaper/books (16.7\%). As shown in table 2 , every four in five respondents rightly said that all age may be the victim of dengue. Fifty-seven percent of the respondents said that there was no human to human transmission of dengue. More than $90 \%$ were sure that the season for dengue transmission was rainy (monsoon). Majority of the respondents (83.3\%) were aware on mode of transmission of dengue as mosquitoes bite. Among them, 92\% had wrong belief that stagnant dirty water was common breeding site of dengue causing mosquitoes. The right answers stated were stagnant clean water (12\%), garbage/trash (70\%), plants/ vegetation $(58 \%)$, water filled containers $(18 \%)$, air cooler/freezer ( $8 \%$ ) and dark places (2\%). Among those who cited mosquitoes, only $2 \%$ rightly said aedes mosquito.

Table 1: Respondents who heard about dengue and their source of information $(n=122)$

\begin{tabular}{|ccc|}
\hline Characteristics & Number $(\mathrm{n}=122)$ & Percentage \\
\hline Yes (heard) & 60 & 49.2 \\
\hline TV/Radio & 39 & 65.0 \\
\hline Newspaper/Books & 10 & 16.7 \\
\hline Health Care Provider & 5 & 8.3 \\
\hline Friends & 6 & 10.0 \\
\hline No (not heard) & 62 & 50.8 \\
\hline
\end{tabular}

Table 2: Awareness on transmission characteristics of dengue $(n=60)$

Characteristics Number $(n=60) \quad$ Percentage

Age Group of Victim of Dengue

Right

Wrong

Human to Human Spread

Right

Wrong

Major Season of Transmission

Right

Wrong

Everybody at risk Dengue Infection

Right

Wrong

2

Mode of Transmission (Multiple response)

\begin{tabular}{lll} 
Mosquito Bite & 50 & 83.3 \\
Stagnant clean water & 6 & 12.0 \\
\hline Garbage/ Trash & 35 & 70.0 \\
\hline Stagnant Dirty Water & 46 & 92.0 \\
\hline Plants / Vegetation & 29 & 58.0 \\
\hline Water Filed Container & 9 & 18.0 \\
\hline Air Cooler / Freezer & 4 & 8.0 \\
\hline Dark Place & 1 & 2.0 \\
\hline Dirty Drinking Water & 5 & 8.3 \\
Files & 1 & 1.7 \\
\hline Rat & 1 & 1.7 \\
\hline Pig & 2 & 3.3 \\
Polluted Air & 1 & 1.7 \\
Blood & 1 & 1.7
\end{tabular}

As shown in figure 1 , the common symptoms of dengue to which people were aware was fever (80\%), headache (51.7\%), myalgia/arthralgia $(36.7 \%)$ and retro-orbital pain $(6.7 \%)$ etc. 
Figure 1: Awareness on clinical features of dengue (Multiple response) $(n=60)$

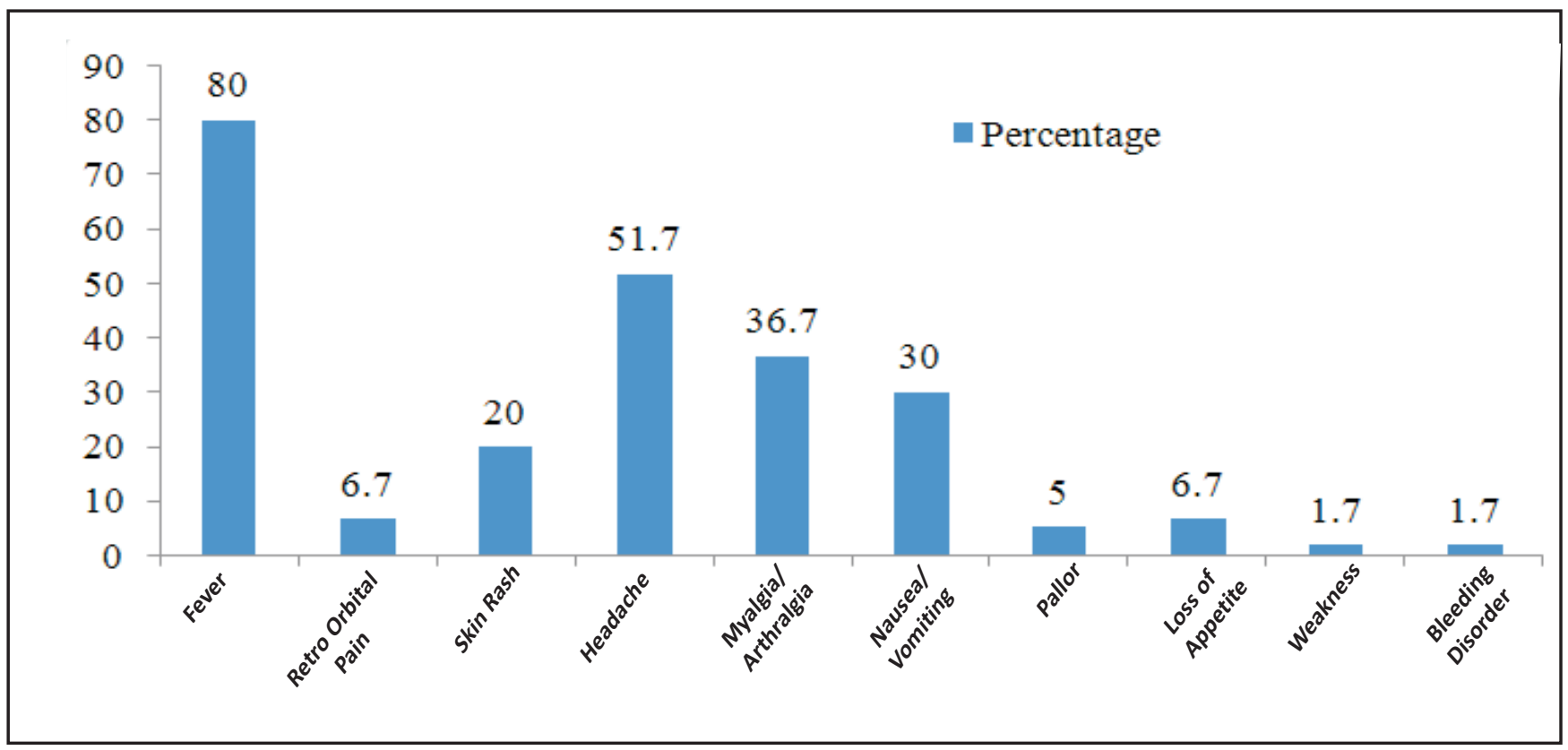

Table 3: Awareness on treatment characteristics of dengue $(n=60)$

Characteristics

\section{Treatment Available}

Right

Wrong

Dengue Patient may Die if no Immediate Treatment

Right

Wrong

8

Chance for re-occurrence of Dengue

Right

Wrong

Strong and Healthy Person Had no Dengue Infection

Right

Wrong

There is Complete Recovery After Dengue Infection

Right

Wrong 
As shown in table 3, 68\% were aware about availability of treatment of dengue. Almost $87 \%$ said that without proper immediate treatment, the dengue patient may die. Almost $27 \%$ said that re-occurrence of dengue is possible. Almost $92 \%$ had wrong belief that strong and healthy persons never contracted dengue. Eight out of ten rightly said that there is complete recovery after dengue infection.
As shown in table 4 , almost $91.7 \%$ were aware that dengue is preventable. Ninety-nine percent felt that their role was important to control dengue. Majority responded mosquito control was the one of the important steps in controlling dengue(83.3\%). Almost $72 \%$ had wrong belief on availability of dengue vaccine. The common methods of dengue prevention cited were use of spray $(51.7 \%)$, use of coil smoke (38.4\%), window/door screen (38.4\%), prevent clean water stagnation $(85.2 \%)$, use of bed nets $(81.8 \%)$ and covering water container (30.1\%) etc.

Table 4: Awareness on prevention characteristics of dengue $(n=60)$

\begin{tabular}{|c|c|c|}
\hline Characteristics & Number $(n=60)$ & Percentage \\
\hline \multicolumn{3}{|l|}{ Dengue Prevention Possible } \\
\hline Right & 55 & 91.7 \\
\hline Wrong & 5 & 8.3 \\
\hline \multicolumn{3}{|c|}{ Your Role Important to Control Dengue } \\
\hline Right & 58 & 96.7 \\
\hline Wrong & 2 & 3.3 \\
\hline \multicolumn{3}{|c|}{ Mosquitoes Control is The One Method of Dengue Control } \\
\hline Right & 50 & 83.3 \\
\hline Wrong & 10 & 16.7 \\
\hline \multicolumn{3}{|l|}{ Vaccine Not Available for Dengue } \\
\hline Right & 17 & 28.3 \\
\hline Wrong & 43 & 71.7 \\
\hline \multicolumn{3}{|c|}{ Dengue Prevention Methods (Multiple Response) } \\
\hline Spray & 31 & 51.7 \\
\hline Coil & 23 & 38.4 \\
\hline Bed-Net & 49 & 81.8 \\
\hline Window and Door Screen & 23 & 38.4 \\
\hline Cleaning House & 53 & 88.5 \\
\hline Covering Body with Clothes & 31 & 51.8 \\
\hline Prevent Clean Water Stagnation & 51 & 85.2 \\
\hline Covering the Container & 18 & 30.1 \\
\hline Change Water Twice in a Week & 23 & 38.4 \\
\hline Fan Use & 3 & 5.0 \\
\hline Smoke to Drive Away Mosquitoes & 9 & 15.0 \\
\hline Phenol Use & 6 & 10.0 \\
\hline
\end{tabular}

Figure 2: Practices related to prevention of dengue ( $n=122)$ (Multiple response)

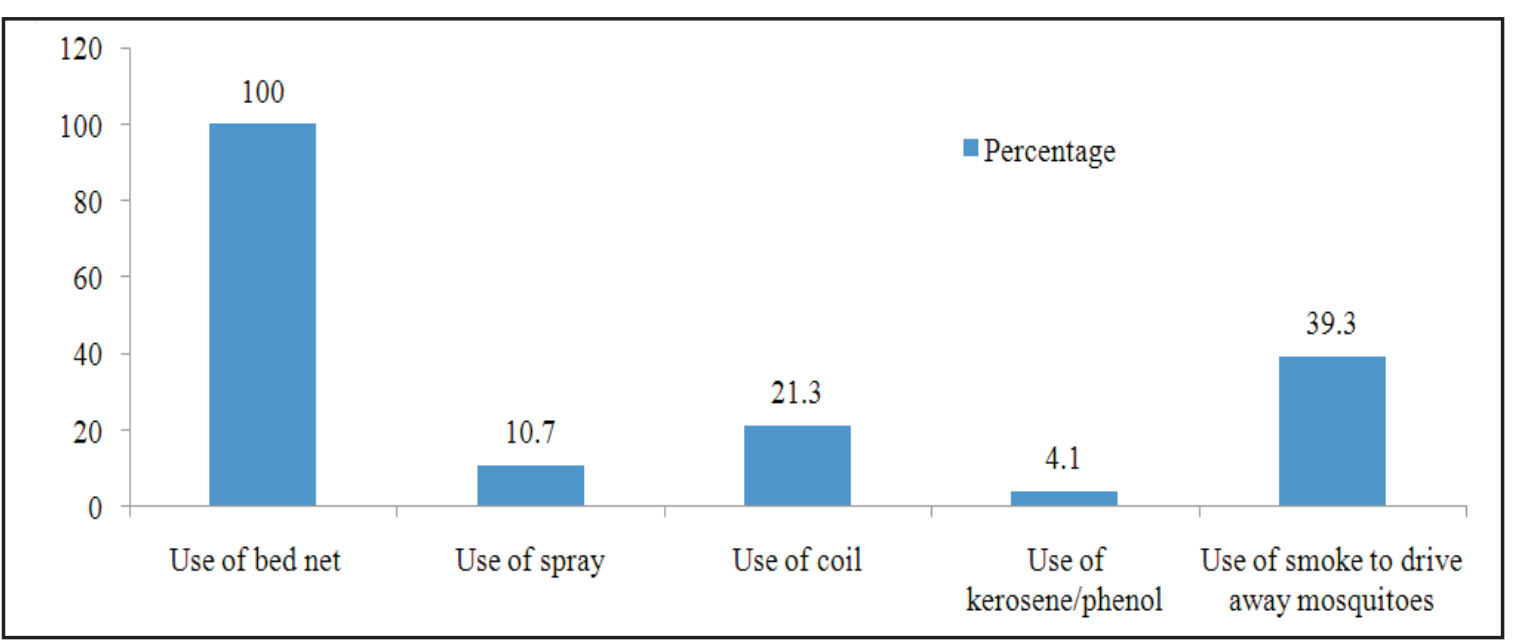


As shown in figure 2 , all the respondents had used bed nets but only $19 \%$ used it both during day and night. Among them only 3.3\% had LLITN (Long Lasting Insecticides Treated Net). Use of smoke to drive away mosquitoes (39.3\%), use of coil $(21.3 \%)$, and use of spray $(10.7 \%)$ were someother preventive practices.

As shown in table 5 , gender $(p<0.001)$, ethnicity $(p=0.004)$, educational status of the respondents $(p=0.020)$ and poverty status $(p=0.006)$ had significant association with respondent being aware about dengue. The odds of being aware about dengue among male was six times higher $(O R=6.168$,

\section{DISCUSSION}

We found agriculture (45.9\%) a major occupation in the present study which is different from a study by Milan Lopchan et $a{ }^{5}{ }^{5}$ where $87 \%$ were housewives. Another study conducted by Ashok etal ${ }^{9}$ is also different from our study where majority (44\%) were housewives. Regarding the history of dengue, two percent were found to have dengue contracted outside the country though no history of death due to dengue was reported. Similar results from Chitwan by Milan Lopchan et al $^{5}$ reported $1 \%$. A study conducted by Anita Acharya et al $^{6}$ found family members $(12.28 \%)$, neighbors

Table 5: Association between awareness about dengue with different variables ( $n=122)$

\begin{tabular}{|c|c|c|c|c|}
\hline \multirow{3}{*}{ Characteristics } & \multicolumn{3}{|c|}{ Awareness About Dengue } & \multirow{3}{*}{ P Value } \\
\hline & Yes & No & Chi-Square & \\
\hline & $n(\%)$ & $n(\%)$ & & \\
\hline \multicolumn{5}{|l|}{ Gendar } \\
\hline Male & $49(65.3)$ & $26(34.7)$ & 20.324 & $<0.001$ \\
\hline Female & $11(23.4)$ & $36(76.6)$ & & \\
\hline \multicolumn{5}{|l|}{ Ethnicity } \\
\hline Brahmin/Chhetri & 31 (68.9) & 14 (31.1) & & \\
\hline Terai Caste & $16(36.4)$ & $28(63.6)$ & 11.15 & 0.004 \\
\hline Other & 13 (39.4) & $20(60.6)$ & & \\
\hline \multicolumn{5}{|l|}{ Marital Status } \\
\hline Married & $47(46.5)$ & $54(53.5)$ & 1.643 & 0.20 \\
\hline Never Married & 13 (61.9) & $8(38.1)$ & & \\
\hline \multicolumn{5}{|l|}{ Poverty Status } \\
\hline Below Poverty Line & $20(35.7)$ & $36(64.3)$ & 7.510 & 0.006 \\
\hline Above Poverty Line & $40(60.6)$ & $26(39.4)$ & & \\
\hline
\end{tabular}

$\mathrm{Cl}=2.70-14.08)$ than female. Age and marital status had no significant association with awareness about dengue. Practices like good natural light inside the household had significant association with dengue awareness $(p=0.002)$. But, other practices like drainage system, history of travel outside the country since last one year, flower vases, paddy field near the household, tires in the household, big plant nearby household and use of mosquito coil to drive away the mosquitoes had no significant association with dengue awareness in this study.
(38.59\%), relatives $(12.28 \%)$ and others $(12.28 \%)$ being contracted with dengue. In the present study, $49.2 \%$ had heard about dengue. The respondents being aware of dengue were higher (90\%) in a study by Anita Acharya et al ${ }^{9}$. In another study from East Delhi urban area, 82.3\% were reported to be aware of dengue. ${ }^{18}$ In a study done in Brazil, $78 \%$ respondents knew about dengue, whereas in a study in Thailand, knowledge about dengue was $67 \% .{ }^{11}$ The major source of information was TV/Radio (65\%) in this study which is supported by the study of Milan Lopchan et $\mathrm{al}^{5}$ (83\%), Anita Acharya et al $^{6}(59 \%)$, Syed et al, ${ }^{12}$ Shuaib et al, ${ }^{13}$ Itrat et al, ${ }^{14}$ Hairi et al ${ }^{15}$ and Rozilawati $\mathrm{H}$ et al. ${ }^{16}$ However, Nalongsack et 
$\mathrm{al}^{17}$ found friends and relatives (43.9\%), Priyadarsini SP et $\mathrm{al}^{7}$ found newspaper (66.67\%) as the main sources of information regarding dengue.

Almost 92\% were sure that the season for dengue transmission was rainy (monsoon). In contrast to this a study by Milan Lopchan et al, $^{5}$ the majority $(42.7 \%)$ revealed summer season for dengue transmission. In this study, majority of the respondents (83.3\%) were aware on mode of transmission of dengue as mosquitoes bite. This finding is supported by research conducted by Syed et $\mathrm{al}^{11}(93 \%)$, Milan Lopchan et $\mathrm{al}^{5}(77.4 \%)$, Priyadarsini SP et $\mathrm{al}^{7}$ (66.67\%), Anita Acharya et $\mathrm{al}^{6}$ (68\%), a study done in Delhi ${ }^{18}$ and Brazil. ${ }^{19}$ However, another study conducted by Kumar et $a l^{20}$ in India revealed that $66.6 \%$ of the respondents were ignorant about the mode of transmission. In the present study, only two percent rightly said that the mosquito is day biter. The awareness on biting time is higher in study by Koenraadt et al $^{8}$ which revealed that $67 \%$ righty cited it as a day biter. In the present study, majority of the respondents (92\%) had wrong belief that stagnant dirty water was common breeding sites. Other than this, $12 \%$ rightly said stagnant clean water followed by air cooler/freezer (8\%) and water filled container (18\%). A study by Milan Lopchan et $\mathrm{al}^{5}$ cited clean stagnant water (44.8\%), bucket and cans (75.9\%), tires (69.7\%), flower pot (65.5\%), water tank (63.4\%) and air cooler (26.9\%). Similarly, another study by Syed, et $\mathrm{al}^{11}$ revealed that most important breeding places for the mosquito were reported as house drains (54.9\%), garbage (46.3\%) and water jars (36.1\%). Similar findings are present in a research done by Kumar et $\mathrm{al}^{19}$ and Itrat et al. ${ }^{13} \mathrm{~A}$ research conducted by Matta et $\mathrm{al}^{21}$ revealed that coolers (42.4\%) as the most probable breeding site. The common symptoms reported in this study were fever (80\%), headache (51.7\%), myalgia/arthralgia (36.7\%), and retro-orbital pain $(6.7 \%)$ which is supported by Milan Lopchan et al, ${ }^{5}$ Koenraadt et $\mathrm{al}^{8}$ and Matta et al. ${ }^{20}$ Another supporting finding is present in Syed et al ${ }^{11}$ and Shuaib et al. ${ }^{12} \mathrm{~A}$ study of East Delhi, showed that $92 \%$ knew about fever followed by headache as a symptom of dengue. ${ }^{17}$ Similarly, in another study done in a suburb of Brazil, $73.1 \%$ knew about fever. ${ }^{18}$ In this study, majority (91.7\%) were aware that dengue is preventable and $96.7 \%$ felt that their role was important for its prevention. About $83.3 \%$ respondents stated that controlling mosquitoes breeding site was important steps to prevent dengue transmission. For this, majority responded that preventing water stagnation $(85.2 \%)$, using bed net $(81.8 \%)$, use of spray $(51.7 \%)$, covering water container $(30.1 \%)$, use of coil smoke (15\%) and use of screen on doors and windows (38.4\%) can control the dengue. However, in a study by Priyadarshan SP et al,' only very few respondents were aware about the preventive measures like using bed nets (23.3\%), spraying (16.67\%) and use of coil smoke (10\%). Similarly, in a study by Milan Lopchan et al $^{5}$ at Chitwan all were aware regarding prevention of mosquitoes bite. The present study is supported by the study of Anita Acharya et $\mathrm{al}^{6}$ where, majority (70.3\%) knew about mosquito repellents like mat, liquid vapourisers, coils and more than half $(55.7 \%)$ mentioned that cleaning of the house as an important preventive practice.

In terms of prevention practices, use of bed nets have been practiced by all however on $19 \%$ used it both during day and night time in the present study. Among them only $3.3 \%$ had LLITN (Long Lasting Insecticide Treated Nets). Other measure being practiced were use of smoke to drive away mosquitoes (39.3\%), use of coil (21.3\%), and use of spray (10.7\%). This is supported by Milan Lopchan et al $^{5}$ where all were aware about the use of mosquito net for preventing from mosquito bite but $70 \%$ were unaware about the use of mosquito net at day time; followed by coil/mat/liquid use (99.4\%), spray of insecticide (80.4\%), screening the doors and windows $(79.7 \%)$ as removing the stagnant water $(79.0 \%)$, wearing long sleeve or whole body covering clothes $(70.6 \%)$, cleaning the surrounding (66.4\%) and use of mosquito repellent (32.9\%). Thirty-six percent knew the frequency of air cooler cleaning as twice a week. In the same way $5.4 \%$ had knowledge about changing water of open container weekly. As Priyadarsan SP et $\mathrm{al}^{7}$ the most commonly practiced preventive measures was use of mosquito nets (23.33\%), repellents (10\%) and spraying (16.67\%). In a study done in Pondicherry, South India almost everyone (99.3\%) used some personal protection measures. ${ }^{22}$ Similarly in a study by Anita Acharya et al ${ }^{6}$ common preventive practices prevalent in the community were mosquito repellents (59\%), prevention of water stagnation around the house $(29 \%)$, spraying of insecticide (11\%) and putting oil in their coolers (19\%). Only 5.5\% used mosquito net. About three percent people did not practice any preventive measure. Among those using mosquito repellents and spraying, majority $(77 \%)$ did during night time. In this study, gender role $(p<0.001)$, ethnicity $(p=0.004)$, educational status of the respondents $(p=0.020)$, and poverty status $(p=0.006)$ is significantly associated with awareness on dengue. Males were more aware $(\mathrm{OR}=6.168, \mathrm{Cl}=2.70-14.08)$ than females. However, with age and marital status of respondents the awareness on dengue is not associated $(p=0.793$ and 0.20 respectively). In a study by Milan Lopchan et al, ${ }^{5}$ the level of knowledge regarding dengue is statistically significant with age $(p=0.005)$, sex $(p=0.003)$, marital status $(p=0.019)$, education of the respondents $(p=0.000)$ and participation in dengue awareness program $(p=0.007)$. This finding is similar to the research conducted by Koenraadt et $\mathrm{al}^{8}$ in Thailand which revealed that sub district, sex, age and education were significantly related with overall knowledge of dengue. Another study supporting this finding was conducted by Syed et $\mathrm{al}^{11}$ in Pakistan revealed that knowledge scores were found 
to have significant association with education $(p=0.004)$. Similarly, practice of natural light inside the house had significant association with dengue awareness $(p=0.002)$. But, other practices like drainage system $(p=0.78)$, history of travel outside the country since last one year $(p=0.345)$, presence of flower vases $(p=0.179)$, paddy field near the household $(p=0.86)$, tires in the household $(p=0.35)$, big plant near the household $(p=0.79)$ and use of mosquito coil to drive away the mosquitoes $(p=0.925)$ had no significant association with awareness on dengue. Similar finding was revealed in the study conducted by Anita Acharya et $\mathrm{al}^{5}$ where a gap was seen between knowledge and preventive practices.

\section{CONCLUSION}

There is a lack of awareness regarding dengue in the study participants. Prevention practices are also not satisfactory in both among those who are aware or unaware. Mass media like TV/Radio has important role in spreading awareness among the population. Improvement of prevention practices for dengue transmission must be emphasized. As there was history of dengue contracted outside the country, the chances of increased risk of dengue spread cannot be ignored.

\section{RECOMMENDATIONS}

There is need of public education program to address the improvement in awareness regarding dengue. Mass media like TV/Radio has important role in spreading awareness among the population. Strengthening the dimensions of mass media is vital in dengue control. Education program should be organized in different areas such as schools, colleges, corporate house, banks and public places. People were still unaware about dengue vector and that it bites in day time and breeds in stagnant clean water. So, method of prevention and awareness should focus on clearance of stagnant clean water inside and outside households like flower vases, coolers, tires and containers left long period of time. Therefore the control programs should be monitored regularly. Further research related to disease, vector management, factors hindering the practices and behavioral change is needed in order to develop and implement effective and reliable dengue prevention and control program.

\section{LIMITATION OF THE STUDY}

Due to the time and resource constraints the study has been conducted only in a VDC of Morang district and hence it might not be generalizable to the whole endemic area in Nepal.

\section{ACKNOWLEDGEMENTS}

We would like to acknowledge all respondents for their support, time and participation. We would also like to acknowledge VDC secretary of Haraincha Village Development Comittee.

\section{CONFLICT OF INTEREST}

We declare no conflict of interest.

\section{REFERENCES:}

1. Cameron P. Simmons et al, "Current Concepts Dengue", The New England Journal of Medicine 366;15 nejm.org April 12, 2012

2. Comprehensive Guidelines for Prevention and Control of Dengue and Dengue Haemorrhagic Fever By WHO SEARO 2011

3. "National Dengue Guidelines for Clinical Management, Prevention and Control", Epidemiology and Disease Control Division, Department of Health Services, Ministry of Health \& Population, Kathmandu, Nepal 2011

4. Dengue and severe Dengue, Fact sheet $N^{\circ} 117$, November 2012, www. who.int/mediacentre/factsheets/fs117/en/index.html

5. Milan Lopchan, Bhaumika Sharma, Sudhir Regmi, Bijay Aryal, Mamata Sharma, "Knowledge and attitude of Dengue Fever among clients from Dengue prevalent areas",International Journal of Pharmaceutical and Biological Archives 2012;3(6): 1383-1388)
6. Anita Acharya, K. Goswami, S. Srinath \& A. Goswami "Awareness about dengue syndrome and related preventivepractices amongst residents of an urban resettlement colony of south Delhi",J Vect Borne Dis 42, September 2005, pp 122-127

7. Priyadarsini SP, Nayeem RA, Kannan C. "Study on awareness and prevention of dengue fever in a selected rural area, Salem, Tamil Nadu- descriptive longitudinal study" Int J Health Sci Res. 2014;4(9):14-20

8. Koenraadt CJM, Tuiten W, Sithiprasasna R, Kijchalao U, Jones JW \& Scott TW "Dengue knowledge and Practices and their impact on Aedes Aegypti populations in Kamphaeng Phet, Thailand" American Journal of Tropical Medicine and Hygiene 2006 74(4): 692-700

9. Ashok KA, V R, Manavalan R, Tewari R, Arunachalam SC, Ayanar N, Krishnamoorthi K, R. Tyagi BK "Studies on Community Knowledge and Behavior following a Dengue Epidemic in Chennai city, Tamil Nadu, India" Tropical Biomedicine 2010, 27(2): 330-336 
10. Nepal Demographic Health Services, Population division, Ministry of Health and Population, 2011

11. Swaddiwudhipong $\mathrm{W}$, Lerdlukanavonge $\mathrm{P}$, Khumklam $\mathrm{P}$, Koonchote $S$, Nguntra P, Chaovakiratipong C "A survey of knowledge, attitude and practice of the prevention of dengue hemorrhagic fever in an urban community of Thailand" Southeast Asian J Trop Med Pub HIth 1992; 23(2): 207-211

12. Syed M, Saleem T, Syeda UR, Habib M, Rehan Z, Bashir A, Rabbani M., Saleem S. "Knowledge, Attitudes and Practices regarding Dengue Fever among Adults of High and Low Socioeconomic groups" Students' Corner 2010, 60(3): 243-247

13. Shuaib F, Todd D, Campbell-Stennett D, Ehiri J, Jolly PE "Knowledge, Attitudes and Practices regarding Dengue Infection in Westmoreland, Jamaica" West Indian Medical Journal 2010, 59(2):139-146

14. Itrat A, Khan A, Javaid S, Kamal M, Khan H, Javed S, Kalia S...Jehan I "Awareness and Practices regarding dengue fever among the adult population of dengue hit cosmopolitan" Open Access Freely available online 2008 3(7): e2620. Available from: http:// www.ncbi.nlm.nih. gov/pubmed/18612437

15. Hairi F, Onq CH, Suhaima A, Tsung TW, Ahmad MAA, Sundaraj C \& Soe MM "Knowledge, Attitude and Practices (KAP) Study on Dengue among Selected Rural Communities in the Kuala Kangsar District" Asia-Pacific Journal of Public Health 2003 15(37):37-43
16. Rozilawati H, Zairi J, Adnan CR "Seasonal abundance of Aedes albopictus in selected urban and suburban areas in Penang, Malaysia" Trop Biomed 2007; 24: 83-94

17. Nalongsack S, Yoshida Y, Morita S, Sosouphanh K, Sakamoto J "Knowledge, attitude and practice regarding dengue among people in Pakse, Laos" Nagoya J Med Sci 2009; 71: 29- 37

18. Gupta P, Kumar P, Aggarwal OP "Knowledge, attitudes and practices related to dengue in rural and slum areas of Delhiafter the dengue epidemic of 1996"J Com Dis 1998; 30(2):107-112

19. Degallier N,Vilarinhos PT, deCarvalho MS, Knox MB,Caetano J Jr “People's knowledge and practice about dengue, its vectors, and control means in Brasilia (DF), Brazil: its relevance with entomological factors"J Am Mosq Contr Assoc 2000;16 (2): 114-123

20. Kumar AV, Rajendran R, Manavalan R, et al "Studies on community knowledge and behavior following a dengue epidemic in Chennai city, Tamil Nadu, India" Trop Biomed 2010; 27: 330-336

21. Matta S, Bhalla S, Singh D, Rasania SK \& Singh S "Knowledge, Attitude and Practice (KAP) on Dengue Fever: A Hospital based study" Indian Journal of Community Medicine 2006 31(3):185-186

22. Snehalatha KS, Ramaiah KD, Vijay Kumar KN, Das PK "The mosquito problem and type and costs of personal protection measures used in rural and urban communities in Pondicherry region, south India." Acta Tropica 2003; 88(1): 3-9 